\title{
Effect of angle stimulation during development on adult discrimination ability in rats
}

\author{
A. JOHN ERNST, RANDALL YEE, and DENICE DERICCO \\ Washington State University, Pullman, Washington 99163
}

\begin{abstract}
Hooded rats were reared in very restricted environments with angular, curved, or white-field stimulation. The extent of transfer from this exposure was assessed in adulthood by testing subjects for (a) learning ability in form, brightness, and pattern discrimination tasks, and (b) exploration and activity differences in an open field. The angle-reared group performed better than the other two rearing groups in all three discrimination tasks. Moreover, the curved and white-field groups were equivalent. These learning differences did not appear to result from differences in (a) exploration or activity or (b) dependence on kinesthetic cues. The results demonstrated that one type of early visual stimulation produced transfer to discrimination tasks that varied in difficulty and in degree of relevancy to the rearing forms. This effect was related to the results and interpretations from previous form-rearing studies. Three interpretations were proposed for this transfer and for the advantage of angular vs. curved stimulation.
\end{abstract}

The purpose of this study was to test the hypothesis that early visual experience might have effects that are not specific to particular rearing forms. Previous studies with rats have shown that exposure to forms during rearing (e.g., circles and triangles) can have a significant impact on learning a form discrimination task involving the same or similar forms (e.g., Bennet \& Ellis, 1968; Forgus, 1958a, b; Gibson \& Walk, 1956; Kerpelman, 1965). However, no transfer has been found when the rearing and test forms were very different (Bennett, Anton, \& Levitt, 1971; Gibson, Walk, Pick, \& Tighe, 1958). A common interpretation for this lack of transfer was that the subjects in studies that had found transfer had learned to pay attention to visual cues which later became the basis for the learned discrimination (Bennett et al., 1971; Gibson, 1969, pp. 258-260).

In contrast to the stimulus-specific effects found in the previous studies, a more general transfer has been found in studies involving greater restriction and using rearing and test stimuli that were quite different (Cool, 1967; McCall \& Lester, 1969; Cool \& Hake, Note 1). In these studies, rats reared with angles on their cages performed better than curvereared in both a square-triangle and circle-ellipse discrimination. This result (a) was clearly inconsistent with the hypothesis that the benefit from form rearing was through learning to pay attention to specific visual cues and (b) suggested the hypothesis that early visual experience with angles might have effects that were not specific to particular rearing

This research was supported in part by Grant 10C-2474-8018 from the Washington State University Graduate Research Committee. Requests for reprints should be sent to A. John Ernst, Department of Psychology, Washington State University, Pullman, Washington 99163. forms. However, the angle-rearing studies did not adequately test this hypothesis, because they failed to test for (a) transfer beyond form discrimination or (b) the importance of exploratory behavior and activity for learning differences (see Woods, Ruckelshaus, \& Bowling, 1960).

Support for a more generalized transfer effect is provided by studies involving enrichment and pattern restriction. For example, early enrichment can have dramatic effects on neuroanatomy and neurophysiology (Rosenzweig, 1971; West \& Greenough, 1972), learning ability (e.g., Rosenzweig, '971), and exploratory behavior and activity (e.g., Smith, 1972). In addition, visual pattern restriction can have a significant impact on visual acuity (Muir \& Mitchell, 1973), feature extracting neurons (Blakemore, 1974), and brain enzymes (Singh, Maki, Johnston, \& Klosterman, 1970).

The results from the angle-rearing, enrichment, and pattern-restriction studies suggested that early visual experience might influence development such that transfer could be found in a variety of discrimination tasks. However, the question remains as to why the two form-rearing studies that tested for this effect failed to find it (Bennett et al., 1971; Gibson et al., 1958). The answer may involve the rearing environments and discrimination tasks used. For example, both studies used environments that provided a great deal of extraneous stimulation which may have masked rearing differences. Moreover, in the Gibson et al. study, the test for transfer was learned very quickly by all subjects.

The second limitation of the angle-rearing studies was the failure to assess the contribution of activity or exploration to learning differences. For example, it had been found that early experience influenced activity and exploration measures and that errors 


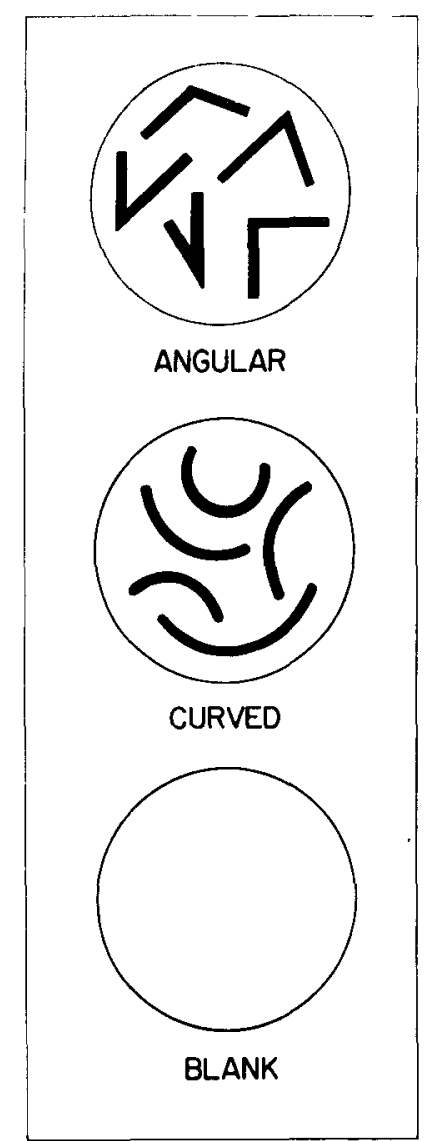

Figure 1. Array of forms used in the three rearing conditions.

were positively correlated with activity levels (Woods et al., 1960).

Thei efore, very restricted environments were used in the present study in conjunction with angular, curved, and white-field stimulation. These rearing stimuli were selected because exposure to angles was more beneficial than exposure to curves (Cool, 1967; McCall \& Lester, 1969). Visual discrimination ability was tested with form, pattern, and brightness discrimination tasks; a range of task difficulty was used (Munn, 1950) to provide a thorough analysis of transfer effects (see Oswalt, 1972). Moreover, the effect of rearing on activity, exploration, and emotionality was assessed with open-field measures.

\section{METHOD}

\section{Subjects}

Sixty-three male hooded rats were obtained from the breeding colony at Washington State University. Hooded rats were used in order to test the generality of the results of previous formrearing studies which had primarily used albino rats (see Henderson, 1968, 1972).

\section{Apparatus}

Rearing cages. All subjects were rassed individually in cans that were $55 \mathrm{~cm}$ long and $23 \mathrm{~cm}$ in diameter, resting on their sides in five rows on a wooden rack The insides of the cans were painted flat black and each can contaned wood shavings on the bottom. There were three $.25-\mathrm{cm}$ holes in the can top to permit fresh air circulation, and a black panel was mounted $i \mathrm{~cm}$ above these holes to prevent visual exploration A water-bottle spout protruded $1.5 \mathrm{~cm}$ into the rear of each can, and a loam washer provided a seal around the spout. Water bottles were placed at the rear of the cans to reduce a problem with the McCall and Lester (1969) study, in which the water bottles were positioned on the Plexiglas fronts, thereby providing additional form stımulation and also pairng water inlake with rearing forms.

The open end of each can was covered with a clear Plexiglas panel. Black paper stımulı were attached to the outside of the panel and covered with white paper that had no notsceable pattern. The array of forms used for the three rearing conditions can be seen in Figure 1. The angular group had five angles that were $.7 \mathrm{~cm}$ wide and from 10 to $15 \mathrm{~cm}$ in combined length for the two rays The curve had five curves that were equated to the angle forms in terms of width and length. The blank group had white paper on their cage fronts. The three rearing groups were alternated on the tearıng rack so that ventılation, temperature, and illumination were counterbalanced across groups. The cage fronts were rotated $90^{\circ}$ once a week during rearing. The rearing room was air conditioned, and extra circulation was provided by three fans. Three 40-W fluorescent bulbs were positioned hor1contally in front of the cages

Discrimination test apparatus. The two-choice discrimination apparatus was $80 \mathrm{~cm}$ long, $20 \mathrm{~cm}$ high, and $28 \mathrm{~cm}$ wide at its broadest point. The startbox $(12 \times 25 \mathrm{~cm})$ opened via a guillotine door into a choice compartment, $55 \mathrm{~cm}$ long. A $25-\mathrm{cm}$ divider separated the two discriminanda at the end of the choice compartment, and a clear Plexiglas door was lowered behind the subject after he entered one of the two compartments. The discriminanda were positioned immediately above a $3-\mathrm{cm}$ hole, through which a rat could obtain a $25 \%$ sucrose solut on if the dipper ladle was up. The sides and boltom of the box were painted light gray, and the end with the discrimınanda was white The top was clear Plexiglas. Two 40-W fluorescent lights were positioned $1 \mathrm{~m}$ above the apparatus.

The six discriminanda consisted of $.3-\mathrm{cm}$ black or gray Plexiglas mounted on $9 \times 13 \mathrm{~cm}$ white Plexiglas panels. The form discriminanda consisted of a $5.5-\mathrm{cm}$-high black equilateral triangle and circle Both curved and angular forms were used for this discrimination in order to counterbalance across angle and curve conditions for specific transfer effects. The brightness discriminanda consisted of black and light gray $5.5-\mathrm{cm}$ squares. The pattern discriminanda consisted of five 8 -cm-long and 6 -cm-wide black wavy paralle! lines positioned either vertically or horizontally with $.6 \mathrm{~cm}$ separation between the lines Wavy lines were used instead of straght lines to reduce any advantage the anglereared group mighi have over the curve group because of previous experience with straight lines

Exploratory test apparatus. The exploratory behavior test apparatus consisted of a $55-\mathrm{cm}$-square chamber with $19-\mathrm{cm}-\mathrm{h}$ gh sides. It was painted white, except for the floor, which had a black grid consisting of 10.6-cm squares The apparatus was covered with glass.

\section{Procedure}

Complete litters of rats were removed from the nursery and placed in a dark room at 8 days of age, before the pups' eyes opened at 22 days of age, the males were separated and placed in one of the three rearng environments using the split-litter technique. The cans were cleaned under dim red illumination every other day during the first 30 days of tearıng and every day after that. Food and water were available ad lıb durıng rearing.

At 95 days of age, the subjects were tested in the open-field apparatus for $20 \mathrm{~min}$. Measures of the number of line crossings and the number of boli excreted were obtained at $30-\mathrm{sec}$ intervals. 
After the open-field test, the subjects were reduced to $85 \%$ of their ad-lib weights and handled for $5 \mathrm{~min}$ per day for 3 days. The subjects were adapted to the discrimination apparatus without stumuli for one session and then shaped to lick sucrose. During three pretraining sessions, the subjects were trained to go from the startbox to one of the two choice compartments, with white panels being used instead of the discriminanda. Subjects from the three rearing groups were then assigned to one of the three discrimination tasks. One-third of the angle-reared subjects were tested with the form discrimination task (circle vs. triangle), one-third with the brightness discrimınation (black vs. gray), and one-third with the pattern discrimination task (vertical vs. horizontal lines). Subjects in each of the other two rearing groups were similarly divided into three test groups so that there were nine independent groups.

During the discrimination sessions, the subjects received 10 trials per day. If a subject made the correct choice, it was allowed $5 \mathrm{sec}$ in the goalbox and was then returned to the startbox for a 20-sec ITI. If a subject made the incorrect choice, a limited correction procedure was used-the subject was allowed two additional chances to obtain reinforcement. After three consecutive incorrect choices, the subjects were placed in the correct goalbox for $5 \mathrm{sec}$. A trial was scored as correct if the subject made the correct response on the initial choice for that trial. Discrimination sessions were continued until a subject reached the criterion of 9 out of 10 correct trials for three out of four sessions or had received 65 discrimination sessions.

The correct stimulus for each pair was counterbalanced across the three discrimination tasks and the three rearing groups, and the left-right position of the correct stimulus was randomized, with five presentations on each side. Five different sequences of leftright were used so that subjects would not learn the correct sequence of left-right positions. The experiment was performed in three replications with 21 subjects per replication. Two or three subjects from each of the nine groups were in each replication. Overall, there were seven subjects per group for a total of 63 subjects.

\section{RESULTS}

Differences in learning ability were assessed by analyses of (a) the number of sessions to learn (b) the number of correct trials per session over all sessions in six Vincentized blocks and over the first 26 sessions, (c) the number of subjects that did not reach the criterion of learning and (d) the tendency to position respond over all sessions in six Vincentized blocks and over the first 26 sessions.

The mean number of sessions needed to reach the criterion of learning can be seen in Figure 2. The angle-reared group learned faster than the blank and curve groups, $F(2,54)=8.70, p<.01$, and this superiority was evident across all three discrimination tasks (Rearing by Task interaction, $\mathrm{F}<1$ ). The three discrimination tasks differed in difficulty, $F(2,54)=6.07, p<.01$. Independent comparisons (Newman-Keuls) of the task differences indicated that the brightness discrimination was learned more quickly than the pattern discrimination, $q(54)=$ $2.94, p<.05$, but that the pattern and form discriminations did not significantly differ in difficulty, $\mathrm{q}(54)=1.95, \mathrm{p}>.05$. The replication analysis indicated that there was a significant difference in sessions-to-learn across the three replications,

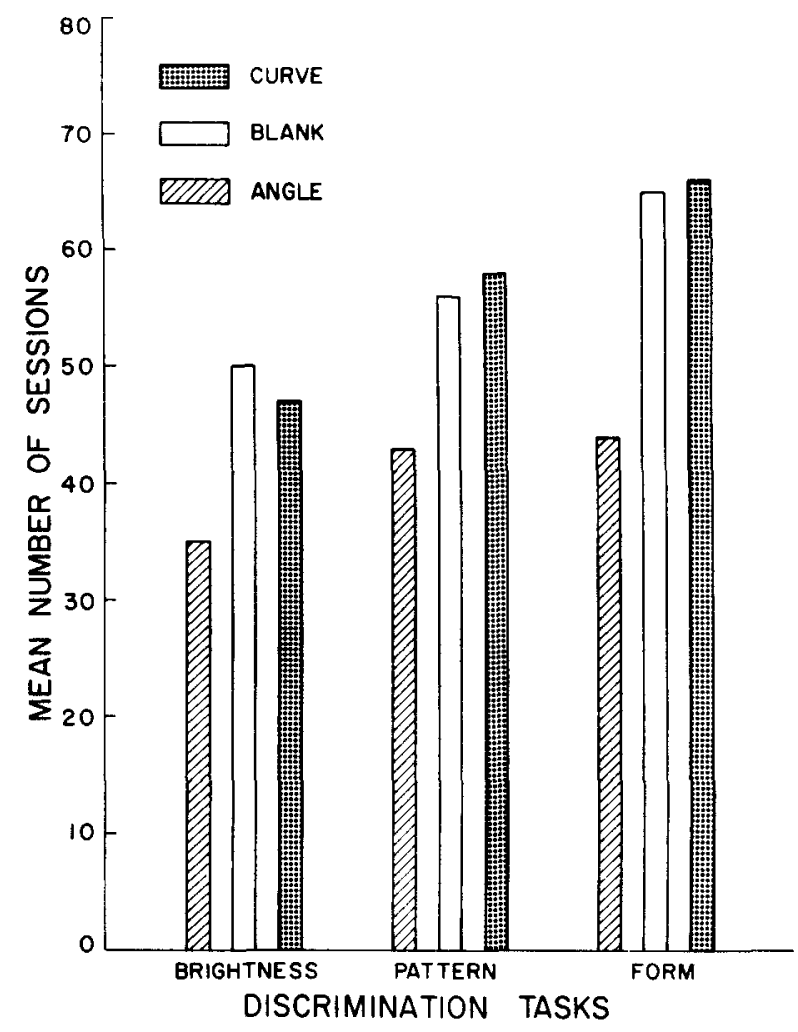

Figure 2. Mean number of discrimination sessions needed to reach the criterion of learning as a function of rearing conditions and discrimination tasks.

$F(2,54)=3.59, p<.05$. However, the relative rate of learning among the three rearing groups did not change over replications (Rearing by Replication interaction, $\mathrm{F}<1$ ).

In order to test for specific transfer effects (i.e., whether angle rearing made the triangle easier to discriminate than the circle), the sessions-to-learn data were analyzed separately for the form discrimination task. While the rearing effect was significant, $F(2,15)=5.2, p<.01$, neither the triangle-circle factor nor the Rearing by Trianglecircle interaction was significant, Fs $<1$.

To compare the rate of learning, the number-ofcorrect-trials-per-session scores were Vincentized into six mean scores for each subject over all sessions. This procedure was used because the number of test sessions ranged from 19 to 65 . These scores (expressed as percent correct and pooled across discrimination tasks) are plotted in Figure 3 for the three rearing groups. The rearing effect was significant, $F(2,54)=3.97, p<.05$. Independent comparisons (Newman-Keuls) indicated that the angle group was superior to the curve group, $q(54)=$ $3.93, p<.05$. However, the blank group did not differ significantly from either of these groups, $p>.05$. There was a significant increase in learning scores over the six blocks, $\mathrm{F}(5,270)=39.16, \mathrm{p}<.01$. 


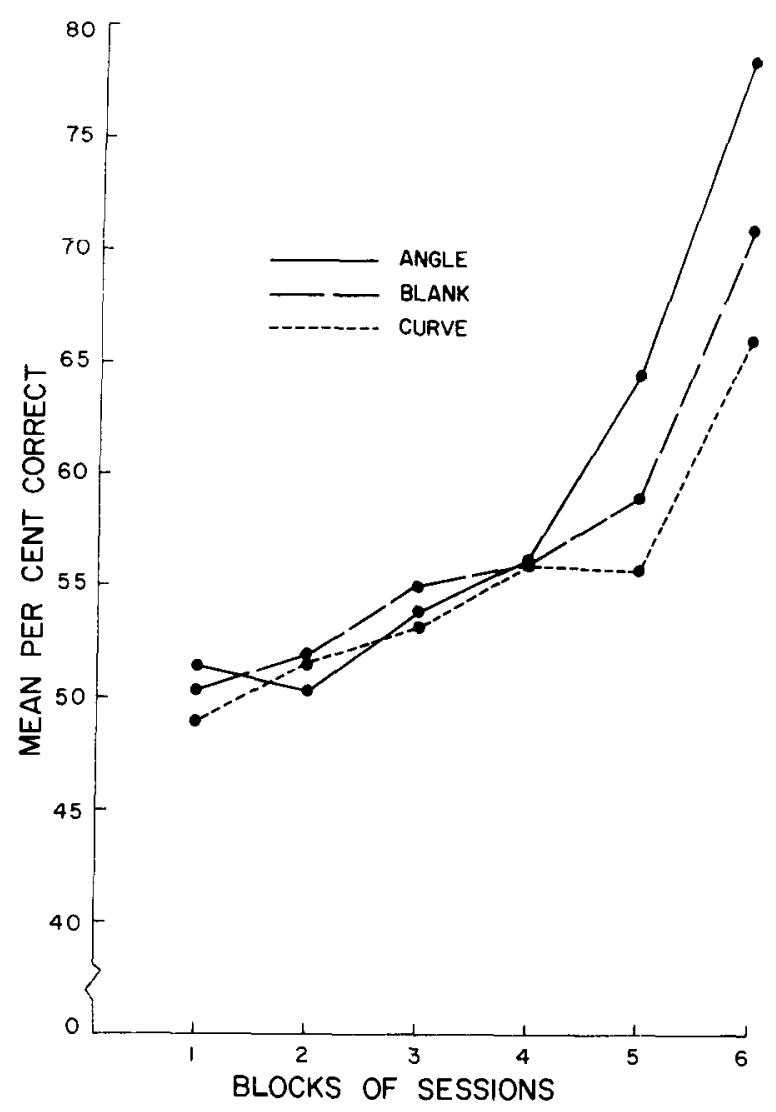

Figure 3. Mean percent correct trials per session over all discrimination sessions in six Vincentized blocks as a function of rearing conditions and pooled across discrimination tasks.

Although the main effect for discrimination tasks was not significant, $\mathrm{F}<1$, there was some indication that the form discrimination task was more difficult that the others [Significant Task by Blocks interaction, $F(10,270)=1.95, p<.05]$. Neither the Rearing by Task interaction nor the Rearing by Task by Blocks interaction was significant, Fs $<1$. The replication factor and the Rearing by Replication interaction were not significant, $\mathrm{p}>.05$.

The learning scores were also analyzed over the first 26 sessions with the mean-number-of-correcttrials-per-session measure. The results of these analyses were very similar to those found with the Vincentized data. The major findings were that (a) the divergence of the angle group from the other two began after the 14th session and (b) the performance of the blank and curve groups was nearly identical.

The number of subjects that did not reach the criterion of learning was related to rearing conditions [angle $=3$, blank $=8$, curve $=11 ; \chi^{2}(2)=6.95$, $\mathrm{p}<.05$ ]. This learning measure was also influenced by the type of discrimination task [brightness $=2$, pattern $=5$, form $\left.=15 ; \chi^{2}(2)=19.4, p<.01\right]$.

Since Cool (1967) had found that curve-reared rats learned a position habit faster than angle-reared ones, position responding was analyzed by recording the number of times during each session a subject went to the most frequently entered side of the twochoice compartment. The scores of each subject over all sessions were then Vincentized into six blocks. There was a significant decline in the tendency to position respond over sessions, $F(5,270)=7.97$, $p<.01$. However, no other main effects were significant, $F s<1$, and no interactions were significant, $p>.05$. Position responding scores were also analyzed over the first 26 sessions, and similar results were found.

In terms of open-field behavior, rearing conditions did not significantly influence the number of line crossings, $p>.05$. There was a significant decline in activity over the 40 intervals, $F(39,2340)=9.7$, $\mathrm{p}<.01$ ), but no interactions were significant, Fs $<1$. The number-of-boli measure was not significantly influenced by rearing conditions, $\mathrm{F}<1$.

\section{DISCUSSION}

The angle group was superior to both the curve and blank groups in all three discrimination tasks. While most of the learning measures indicated that the curve and blank groups were equivalent (sessions to criterion and mean number of correct trials per session over the first 26 sessions), one indicated that the blank group was intermediate to the angle and curve groups (mean number of correct trials per session over all sessions). The finding that the at.gle group was superior to the curve group in form discrimination (regardless of which stimulus was correct) replicates the results of Cool (1967) and McCall and Lester (1969) with a different form discrimination and strain of rats. More importantly, the finding that the angle group was also superior in the pattern and brightness discriminations supported the original hypothesis that early exposure to angles might enhance performance in a variety of discrimination tasks that varied both in difficulty and in degree of relevancy to the rearing forms.

The finding that the angle group was superior in all three tasks was consistent with the results of (a) the two angle-rearing studies, (b) the enrichment studies, and (c) the pattern-restriction studies. However, this effect was inconsistent with the interpretation from previous form-rearing studies, since angle stimulation enhanced learning in a variety of tasks. This outcome also raises the possibility that the effects observed in the form-rearing studies may not have represented specific transfer; this suggestion would be relevant to the differentiation theory of discrimination iearning, which was partially based on these findings and interpretations (Tighe \& Tighe, 1966).

Since the results in this study did not appear to be a function of learning to pay attention to specific 
visual cues, three alternate interpretations for this effect and for the superiority of angle stimulation will now be discussed. The first two are variations on an efficacy interpretation, and the third relates to saliency.

The first interpretation involves the development of perceptual units which could change discrimination capacity. Hebb $(1949,1963)$ proposed that angles and straight lines were basic perceptual elements that were partly innate, partly learned. Exposure to angles and straight lines might have allowed subjects in the angle group to acquire cell assemblies involving these perceptual units during rearing.

A second interpretation relates to the modification of specialized detectors in the visual nervous system. It has been shown that the most effective stimulus configurations for eliciting receptive fields involve straight-line contours rather than curved or circular stimuli (Hubel, 1963; Hubel \& Wiesel, 1962). In addition, exposure to straight-line configurations can program the later functioning of feature-detecting neurons (Blakemore, 1974). These findings suggest (a) that the visual system may have been more responsive to the straight line component of angle stimulation, and (b) that this stimulation may have programmed analyzer mechanisms which in turn produced a more highly developed visual nervous system.

A third interpretation is that angles were a more salient visual stimulus and attracted more attention. This hypothesis is consistent with (a) the finding that human infants tend to fixate more on the vertices of a triangle (Saiapatek \& Kessen, 1966) and (b) Attneave's (1954) theory, which proposed that the essential informational aspects of forms are contained where brightness gradients are sharp and the directions of contours change abruptly. If angles attracted more attention, subjects may have (a) learned to pay attention to visual forms or (b) spent more time viewing angular forms, thereby facilitating the building of cell assemblies or the programming of analyzer mechanisms.

It did not appear that the inferior learning of the curve and blank groups was related to differences in (a) exploration, activity, or emotionality or (b) dependence on kinesthetic cues. In terms of the first factor, rearing conditions did not significantly influence any of the open-field measures. In reference to the second factor, Cool (1967) had shown that rats reared with curves appeared to rely more than angle-reared subjects on kinesthetic cues. However, there was no evidence that this was a significant factor in the present study, since there was no difference between rearing groups in the tendency to position respond.

The differences in task difficulty indicated that with two measures the form discrimination was the hardest, the pattern discrimination was intermediate, and the brightness discrimination was the easiest. A third measure (number of correct trials per session over all sessions) indicated that while the form discrimination was the most difficult, the other two were equivalent. These differences were consistent with previous results (Munn, 1950).

Before the previous conclusions concerning the benefits of angle rearing can be accepted, several issues need to be examined. The first concerns the appropriateness of concluding that angle rearing enhanced learning instead of concluding that curve or blank rearing impaired learning. In the two angle-rearing studies that used colony-reared control groups to provide a "normal" reference point (Cool, 1967; Cool \& Hake, Note 1), it was found that angle-reared rats were equivalent in form discrimination ability to control subjects. Although this equivalency might suggest that in the present study angle rearing produced "normal" perceptual development and that blank or curve rearing produced impairment, a major difficulty with trying to determine whether a particular rearing condition represents enhancement or impairment is that of defining "normal" rearing. For example, one could argue that "normal" colony rearing represents deprivation in contrast to the environment of rats in the wild or in an enriched laboratory setting (the contrast between natural and laboratory rearing has been noted elsewhere, e.g., Boice, 1973; Levine, 1962; Lockard, 1968). This argument would suggest (a) that it would be rather arbitrary to select one level of stimulation (e.g., colony rearing) to represent "normal" rearing, and (b) that most early-stimulation studies could be discussed in terms of deprivation. However, an alternative approach would be to select in each study the rearing condition invc.iving the least stimulation as the baseline condition.

A second issue concerns the appropriateness of comparing the present study with the form-rearing studies, particularly if deprivation was involved in the former. For example, the form-rearing studies could be viewed as involving enrichment because the experimental groups performed better than the colony-reared control groups. However, the difficulty of selecting one level of early stimulation (e.g., colony rearing) as the norm has already been pointed out. In addition, both angle and form rearing can be viewed as deprivation in contrast to an enriched environment or as enrichment in contrast to total isolation. If similar processes are involved, it would seem appropriate to relate the present study to the form-rearing studies.

A third issue involves an apparent conflict between this study and that of McCall and Lester (1969). For example, they found weak evidence that the blank group was superior to the curve group, while the present study found with most of the learning measures that the curve and blank groups were equivalent. However, it is unlikely that this is a 
serious conflict for three reasons: (a) the differences found by McCall and Lester were only marginally significant; (b) the most comparable learning measure in the present study (correct trials per session over all sessions) also suggested that the blank group was intermediate to the angle and curve groups; and (c) the blank group in the McCall and Lester study had water bottles on the cage fronts, thereby providine, more potential form stimulation for the blank $\varepsilon$ oup in that study than in this study.

Theictore, this study showed that exposure to angles enhanced learning in discrimination tasks that varied in difficulty and in degree of relevancy to the rearing forms. These differences did not appear to be attributable to differences in exploratory behavior or to dependence on kinesthetic cues. This effect was consistent with results from the two angle-rearing studies, the enrichment studies, and the pattern-restriction studies. Since this effect was inconsistent with the results and interpretation from previous form-rearing studies which had failed to find transfer when rearing and test stimuli were different, the current findings have important implications for perceptual theories that utilized those results and interpretation. Three possible interpretations were suggested for the effect and for the benefit of angular stimulation.

\section{REFERENCE NOTE}

1. Cool. S. J. \& Hake, H. W. Effects of early visual environments on adult discrimination abilities in the rat. Paper presented at the meeting of the Midwestern Psychological Association. Chicago, April/May 1965.

\section{REFERENCES}

Attneave, F. Some informational aspects of visual perception. Psychologtcal Review, 1954, 61. 183-193.

Bennett, T. L., Anton, B. S. \& Levitt, L. Stimulus relevancy and transfer of perceptual learning. Psychonomic Science, 1971, 25, 159-160.

Bennett. T. L., \& Ellis, H. C. Tactual-kinesthetic feedback from manipulation of visual forms and nondifferential reinforcement in transfer of perceptual learning. Journal of Experimental Psychology, 1968, 77, 495-500.

Blakemore, C. Developmental factors in the formation of feature extracting neurons. In F. O. Schmitt \& F. G. Worden (Eds.). The neurosctences. Cambridge: The M.I.T. Press. 1974.

Borce, R. Domestication. Psychological Bulletin, 1973, 80. 215.230.

Cool, S. J. Some effects of early visual environments on adult discrimination abilities in the rat. Dissertation Abstracts, $1967,27,2522$.

Forgus, R. H. The effect of different kinds of form pre-exposure on form discrimination learning. Journal of Comparative and Physiological Psychology, 1958, 51, 75-78. (a)

Forgus, R. H. The interaction between form pre-exposure and test requirements in determining form discrimination. Journal of Comparative and Physiological Psychology, 1958, 51, 588-591. (b)

GIBSON, E. J. Principles of perceptual learning and development. New York: Appleton-Century-Crofts, 1969.

Gibson, E. J., \& WALK, R. D. The effect of prolonged exposure to visually presented patterns on learning to discriminate them. Journal of Comparative and Physiological Psychology, $1956,49.239-242$

Gibson, E. J., Walk, R. D., Pick, JR., H. L., \& Tighe, T. J. The effect of prolonged exposure to visual patterns on learning to discriminate similar and different patterns. Joumal of Comparative and Physlological Psychology, 1958, 51, 584-587.

He BB, D. O. Organization of behavior. New York: Wiley, 1949.

Heвв, D. O. The semiautonomous process: Its nature and nurture. American Psychologist, 1963, 18, 16.27.

Henderson, N. D. The confounding effects of genetic variables in early experience research: Can we ignore them? Developmental Psychobiology, 1968, 1, 146-152.

Henderson. N. D. Relative effects of early rearing environment and genotype on discrimination learning in house mice. Journal of Comparative and Physiological Psychology, 1972, 70, 243.253 .

Hubel, D. H. Integrative processes in central visual pathways of the cat. Journal of the Optical Society of America, 1963 , 53, 58-66.

Hubel, D. H., \& Wiesel, T. N. Receptive fields, binocular interaction and functional architecture in the cat's visual cortex. Journal of Physiology, 1962, 160, 106-154.

Kerpelman, L. C. Pre-exposure to visually presented forms and nondifferential reinforcement in perceptual learıing. Journal of Experimental Psychology, 1965, 69, 257-262.

LEVINE, S. The psychophysiological effects of infantile stimulation. In E. Bliss (Ed.), Roots of behavior. New York: Harper, 1962.

LOCKARD, R. B. The albino rat: A defensible choice or a bad habıt? American Psychologist, 1968, 23, 734-742.

McCall, R. B. \& Lester, M. L. Differential enrichment potential of visual experience with angles versus curves. Journal of Comparative and Physiological Psychology, 1969 , 69, 644-648.

Muir. D. W. \& Mitchell, D. E. Visual resolution and experience: Acuity deficts in cats following early selective visual deprivation. Science, 1973, 180, 42-422.

Munn. N. L. Handbook of psychological research on the rat. An introduction to animal psychology. Boston: Houghton Mittlin, 1950.

Oswalt, R. M. Relationship between level of visual pattern ditticulty during rearing and subsequent discrimination in rats. Joumal of Comparative and Physiological Psychology, 1972, 81, 122-125.

Rosenzweig, M. R. Effects of environment on development of brain and of behavior. In E. Tobach, L. R. Aronson, \& E. Shaw (Eds.). The biopsychology of development. New York: Academic Press. 1971.

Salapatek, P.. \& Kessen, W. Visual scanning of triangles by the human newborn. Journal of Experimental Child Psychology, 1966, 3, 155-16?

Singh, D., Maki. W. S., JR., Johnston, R. J., \& Klosterman, H. J. Effect of visual pattern restriction in early life on brain enzyme, body weight, and learning in the rat. Nature, 1970 , 228. 471.472 .

Sмiтн, H. V. Eftects of environmental enrichment on openfield activity and Hebb-Williams problem solving in rats. Journal of Comparative and Physiological Psychology, 1972. 80, $163-168$.

Tighe, L. S., \& Tighe, T. J. Discrimination learning: Two views in historical perspective. Psychological Bulletin, 1966, 66. 353-370.

West, R. W., \& Greenough, W. T. Effect of environmental complexity on cortical synapses of rats: Prelıminary results. Behavioral Biology, 1972, 7, 279-284.

Woods, P. J., Ruckelshaus, S. I., \& Bowling, D. M. Some effects of "tree" and "restricted" environmental rearing conditions upon adult behavior in the rat. Psychological Reports, 1960, 6, 191-200.

(Recelved for publication June 26, 1975; revision accepted December 3, 1975.) 